\title{
Spoilage potentials and antimicrobial resistance of Pseudomonas spp. isolated from cheeses
}

\author{
S. Arslan, ${ }^{1}$ A. Eyi, and F. Özdemir \\ Abant Izzet Baysal University, Faculty of Arts and Sciences, Department of Biology, 14280, Gölköy/Bolu, Turkey
}

\begin{abstract}
Pseudomonas spp. are aerobic, gram-negative bacteria that are recognized as major food spoilage microorganisms. A total of 32 (22.9\%) Pseudomonas spp. from 140 homemade white cheese samples collected from the open-air public bazaar were isolated and characterized. The aim of the present study was to investigate the biochemical characteristics, the production of extracellular enzymes, slime and $\beta$-lactamase, and antimicrobial susceptibility of Pseudomonas spp. isolated from cheeses. The identified isolates including Pseudomonas pseudoalcaligenes, Pseudomonas alcaligenes, Pseudomonas aeruginosa, Pseudomonas fluorescens biovar $\mathrm{V}$, and $P$. pseudoalcaligenes ssp. citrulli were found to produce extracellular enzymes, respectively: protease and lecithinase production (100\%), and lipase activity (85.7, 42.9, 100 , and $100 \%$, and nonlipolytic, respectively). The isolates did not produce slime and had no detectable $\beta$-lactamase activity. The antimicrobial susceptibility of the isolates was tested using the disk diffusion method. Pseudomonas spp. had the highest resistance to penicillin G (100\%), then sulphamethoxazole/trimethoprim (28.1\%). However, all Pseudomonas spp. isolates were $100 \%$ susceptible to ceftazidime, ciprofloxacin, amikacin, gentamicin, and imipenem. Multidrug-resistance patterns were not observed among these isolates. In this study, Pseudomonas spp., exhibiting spoilage features, were isolated mainly from cheeses. Isolation of this organism from processed milk highlights the need to improve the hygienic practices. All of the stages in the milk processing chain during manufacturing have to be under control to achieve the quality and safety of dairy products.
\end{abstract}

Key words: Pseudomonas spp., cheese, spoilage potential, antimicrobial susceptibility

Received July 2, 2011.

Accepted September 3, 2011.

${ }^{1}$ Corresponding author: arslan_s3@ibu.edu.tr

\section{INTRODUCTION}

Food spoilage is a serious global problem, especially in developing countries, because of inadequate processing and refrigeration facilities (Bhunia, 2008). Undesirable microorganisms are responsible for the spoilage of dairy products, and pathogens introduced into milk and milk products by unsatisfactory milk production practices, failures in processing systems, or unsanitary practices are of primary concern (Richter and Vedamuthu, 2001). Because of the high nutritional value, water content and near neutral $\mathrm{pH}$ of milk, many spoilage and pathogenic microorganisms can grow in it (Ray, 2004). The predominant gram-negative bacteria such as Pseudomonas spp. may cause spoilage of dairy products (Cousin et al., 2001) due to the production of heat-stable extracellular enzymes (Herrera, 2001). During the pasteurization and UHT treatments many of these enzymes can survive (Ray, 2004; Bhunia, 2008). These can also be detrimental to the quality of cheese by causing bitter or rancid flavors and by impairing the coagulation properties of the milk (Richter and Vedamuthu, 2001). Proteases degrade casein, resulting in bitterness in milk, gelation of UHT-sterilized milk and decreased yields of soft cheese. Lipases catalyze the hydrolysis of triglycerides to free fatty acids and glycerol, which produce flavor defects. Lecithinases are able to disrupt milk fat globule membranes, increasing the susceptibility of milk fat to the action of lipases (Herrera, 2001; Ray, 2004).

Pseudomonas spp. are aerobic, non-spore-forming, gram-negative, rod-shaped bacteria. Some of the species show distinguishable colony morphologies or pigmentation (i.e., the blue-green derivative of phenazine, pyocyanin, and the yellow-green fluorescing pigments; Kıska and Gilligan, 1999). Psychrotrophic pseudomonads are recognized as major spoilage microorganisms based on their extracellular enzymes. The enzymes are generally good indicator of the keeping quality of protein and lipid-rich foods (Cousin et al., 2001). Although microbial spoilage may merely lead to foodstuffs being rendered unpalatable, it can also result in serious and even fatal illness (Hogg, 2005). The Pseudomonas fluorescens group frequently causes the spoilage of dairy 
products. It may gel UHT milk if this is stored above $5{ }^{\circ} \mathrm{C}$. It is also important in patients with burns and cystic fibrosis (Collins et al., 1989; Sorhaug and Stepaniak, 1997). Pseudomonas aeruginosa causes spoilage of foods including blue milk and is pathogenic for humans and animals, often as a secondary infection (Collins et al., 1989). It is now recognized as a common source of many community acquired and nosocomial infections, and affects primarily immunocompromised people and those suffering from cystic fibrosis. The most common infections involve the cornea, skin, urinary tract, and respiratory tract, although infections may occur in essentially all anatomical locations (Yahr and Parsek, 2006). Pseudomonas alcaligenes and Pseudomonas pseudoalcaligenes are ubiquitous, and are opportunist pathogens (Collins et al., 1989).

Many aerobic pseudomonads are resistant to several antibacterial agents (Moore et al. 2006). This subject is of particular medical importance because members of this group, such as $P$. aeruginosa, are serious opportunistic human pathogens (Yahr and Parsek, 2006). The effective antimicrobial agents for the treatment of $P$. aeruginosa infections include some $\beta$-lactams, such as carbenicillin, ticarcillin, third-generation cephalosporins, the synthetic monocyclic $\beta$-lactam aztreonam, carbapenems, the aminoglycosides, and the quinolones. Pseudomonas aeruginosa and other fluorescent Pseudomonas species are in general resistant to $\beta$-lactams (Garrity et al., 2005).

The objectives of the present study were (1) to isolate Pseudomonas spp. from homemade cheese samples collected from the open-air public market; (2) to identify the isolates using biochemical tests; (3) to determine the extracellular enzyme and slime production, and the $\beta$-lactamase activity; and (4) to examine the antimicrobial susceptibility of Pseudomonas spp.

\section{MATERIALS AND METHODS}

\section{Sample Collection}

Approximately 140 samples of homemade white cheeses were randomly collected from the open-air public bazaar over a 6-mo period in Bolu (northwest Turkey). White cheese, a semisoft brined cheese, was produced by traditional methods, frequently from raw cow milk without starter cultures in rural areas. The samples were transported to the laboratory in sterile bags to minimize the possibility of contamination under cold conditions (at $4^{\circ} \mathrm{C}$ ) and analyzed immediately.

\section{Isolation and Identification of Pseudomonas spp.}

A volume of $225 \mathrm{~mL}$ of trisodium citrate was added to the stomacher bags, each of them includes $25 \mathrm{~g}$ of sample, and the samples were homogenized for 2 min by stomacher (BagMixer 400; Interscience, Paris, France). Ten-fold serial dilutions were plated onto cetrimideFucidin-cephaloridine-supplemented Pseudomonas agar base (Oxoid Ltd., Basingstoke, UK) plates (ISO13720:2000). They were incubated at $25^{\circ} \mathrm{C}$ for 24 to 48 h. From each sample, several colonies were randomly chosen and subcultured for biochemical tests on nutrient agar (Merck KGaA, Darmstadt, Germany) plates. Colonies on nutrient agar are usually large $(2-4 \mathrm{~mm})$, flat, spreading, and pigmented. A greenish-yellow or bluish yellow fluorescent pigment may diffuse into the medium. A brown pigment is formed around the colonies (Collins et al., 1989). The presumptive Pseudomonas colonies were identified and confirmed by the following tests: Gram staining, motility, oxidase production, pigment production, ability to grow at $42^{\circ} \mathrm{C}$, gelatin hydrolysis, tryptophan hydrolysis (indol production), utilization of carbohydrates (xylose, trehalose, glucose, arabinose, mannitol, galactose, fructose, and sucrose), and nitrate reduction (Garrity et al., 2005).

\section{Screening of Extracellular Enzyme Producing Pseudomonas spp.}

To determine production of proteases, lipases, and lecithinases, Pseudomonas isolates were plated on agar plates containing the appropriate substrates as described below. Production of proteolytic enzymes was examined on plate count agar (Merck KGaA) containing $10 \%$ skim milk powder. After incubation at $37^{\circ} \mathrm{C}$ for $72 \mathrm{~h}$, plates were flooded with $1 \mathrm{~N} \mathrm{HCl}$ to observe clearance zones (Vermelho et al., 1996). Lipase producers were screened using tributyrin agar (Merck KGaA) plates. These plates were incubated at $30^{\circ} \mathrm{C}$ for $48 \mathrm{~h}$. The activity of the lipase was observed as a zone of hydrolysis around the bacterial colonies (Meghwanshi et al., 2006). Assessment of the production of lecithinase was performed on plate count agar (Merck KGaA) containing $10 \%$ egg yolk emulsion (Oxoid Ltd.). After incubation at $37^{\circ} \mathrm{C}$ for $72 \mathrm{~h}$, plates were observed the presence of colonies surrounded by opaque zones (Bates and Liu, 1963).

\section{Slime Production}

Slime production of all isolates was evaluated by the Congo red agar method (Freeman et al., 1989). In the Congo red test, the medium was prepared with $37 \mathrm{~g} / \mathrm{L}$ of brain heart infusion broth (Oxoid Ltd.), $50 \mathrm{~g} / \mathrm{L}$ of sucrose, $10 \mathrm{~g} / \mathrm{L}$ of agar, and $0.8 \mathrm{~g} / \mathrm{L}$ of Congo red. Congo red stain was prepared as a concentrated aqueous solution and autoclaved at $121^{\circ} \mathrm{C}$ for $15 \mathrm{~min}$ and separately from the other medium constituents, and 
was then added when the agar had cooled to $55^{\circ} \mathrm{C}$. Plates were inoculated and incubated at $37^{\circ} \mathrm{C}$ for 24 h. A positive result was indicated by black colonies on the surface. Non-slime-producing strains developed red colonies.

\section{$\beta$-Lactamase Testing}

$\beta$-Lactamase strips (Fluka Chemie AG, Buchs, Switzerland) for the acidimetric detection of the $\beta$-lactamase activity of all Pseudomonas spp. were used. The test strips were inserted into test tubes with prepared bacterial suspension in saline. A positive result was indicated by the appearance of a yellow color within a time limit (10-15 min). Strips with unchanged red color were considered as negative.

\section{Antimicrobial Susceptibility Testing}

Susceptibility to antimicrobial agents was tested using the disk diffusion method according to Clinical and Laboratory Standards Institute (CLSI, 2007) guidelines. Isolates were inoculated in Mueller-Hinton broth (Merck KGaA) and adjusted to 0.5 McFarland's standard before testing, and then they were plated on Mueller-Hinton agar (Merck KGaA) plates. The following 9 different antimicrobial sensitivity discs (Oxoid Ltd.) were placed on each plate and examined against Pseudomonas isolates recovered from cheese samples: $\beta$-lactams (penicillin G, $10 \mathrm{U}$; piperacillin, $100 \mu \mathrm{g}$; and piperacillin/tazobactam, $110 \mu \mathrm{g}$ ), other $\beta$-lactams (ceftazidime, $30 \mu \mathrm{g}$ ), aminoglycosides (amikacin, $30 \mu \mathrm{g}$ and gentamicin, $10 \mu \mathrm{g}$ ), quinolones (ciprofloxacin, 5 $\mu \mathrm{g}$ ), and other antimicrobial agents including imipenem $(10 \mu \mathrm{g})$ and sulphamethoxazole/trimethoprim $(25 \mu \mathrm{g})$. Plates were incubated at $37^{\circ} \mathrm{C}$ for $24 \mathrm{~h}$. The diameters of inhibition zones were recorded to the nearest millimeter and classified as susceptible, intermediate, or resistant.

\section{RESULTS}

\section{Identification and Biochemical Characteristics of the Isolates}

Thirty-two $(22.9 \%)$ bacterial isolates were obtained from 140 homemade white cheese samples. The predominant isolate was $P$. pseudoalcaligenes (15\%) followed by $P$. alcaligenes (5\%), P. aeruginosa (1.4\%), $P$. fluorescens biovar $\mathrm{V}(0.7 \%)$, and $P$. pseudoalcaligenes subspecies citrulli (0.7\%; Table 1). All Pseudomonas spp. were actively motile after the 24 -h incubation and gave oxidase-positive reaction. They did not reduce nitrate to nitrite and did not hydrolyze tryptophan.
All isolates did not produce acid from trehalose, except P. fluorescens biovar V; however, acid production from other carbohydrates was variable. In addition, all isolates hydrolyzed gelatin, and were able to grow at $42^{\circ} \mathrm{C}$.

\section{Production of Extracellular Enzyme, Slime, and $\beta$-Lactamase}

The most frequent extracellular protease, lipase and lecithinase activities were as follows for P. aeruginosa, P. fluorescens biovar V, P. pseudoalcaligenes, $P$. alcaligenes, and $P$. pseudoalcaligenes ssp. citrulli isolates, respectively: protease and lecithinase production $(100 \%)$, and lipase activity $(100,100,85.7$, and $42.9 \%$, and nonlipolytic, respectively). None of the isolated Pseudomonas spp. produced slime, which is the indicator of pathogenicity. Nevertheless, Pseudomonas isolates did not show $\beta$-lactamase activity. The results of production of the extracellular enzyme, slime, and $\beta$-lactamase for each Pseudomonas spp. isolated from homemade white cheese samples are shown in Table 1.

\section{Antimicrobial Resistance Profiles}

The results of antimicrobial susceptibility of Pseudomonas spp. isolated from cheese are shown in Table 2. According to this, Pseudomonas spp. had the highest resistance to penicillin G (100\%), then sulphamethoxazole/trimethoprim (28.1\%). However, all Pseudomonas spp. isolates were $100 \%$ susceptible to ceftazidime, ciprofloxacin, amikacin, gentamicin, and imipenem. Multidrug-resistance patterns were not observed among these isolates.

\section{DISCUSSION}

Pseudomonas spp. isolated from homemade white cheese samples were well-characterized in this study on the basis of several biochemical characteristics. The isolates of Pseudomonas spp. were detected in $22.9 \%$ of the samples. One of the microbiological components of raw milk can be psychrotrophic microorganisms, mainly belonging to the genus Pseudomonas, which are responsible of the spoilage of milk and dairy products at low temperature (Ray, 2004).

Reported previous studies were focused on isolation of Pseudomonas spp. from raw milk samples and dairy products. Even though various Pseudomonas spp. have been isolated from raw milk samples, the $P$. fluorescens group is the most frequently involved in dairy products by the depredation of milk (Wiedmann et al., 2000; Dogan and Boor, 2003). Gennari and Dragotto (1992) reported that prevalence of Pseudomonas spp. was $86 \%$ from the foodstuffs and environmental samples, and 


\begin{tabular}{|c|c|c|c|c|c|c|c|}
\hline Strain & Identification & Pigmentation & $\begin{array}{l}\text { Protease } \\
\text { activity }\end{array}$ & $\begin{array}{l}\text { Lipase } \\
\text { activity }\end{array}$ & $\begin{array}{l}\text { Lecithinase } \\
\text { activity }\end{array}$ & $\begin{array}{c}\text { Slime } \\
\text { production }\end{array}$ & $\beta$-Lactamase \\
\hline 3/PS1 & Pseudomonas pseudoalcaligenes & Light brown & + & + & + & - & - \\
\hline 5/PS1 & P. pseudoalcaligenes & Light brown-yellow & + & + & + & - & - \\
\hline 6/PS2 & P. pseudoalcaligenes & Yellow & + & + & + & - & - \\
\hline 7/PS1 & P. pseudoalcaligenes & Cream & + & + & + & - & - \\
\hline 9/PS1 & P. pseudoalcaligenes & Yellow & + & + & + & - & - \\
\hline 13/PS1 & Pseudomonas alcaligenes & Light brown & + & + & + & - & - \\
\hline 18/PS2 & P. pseudoalcaligenes & Light brown & + & + & + & - & - \\
\hline 24/PS1 & P. pseudoalcaligenes & Light brown & + & + & + & - & - \\
\hline 39/PS2 & P. alcaligenes & Light brown & + & + & + & - & - \\
\hline 40/PS1 & P. pseudoalcaligenes & Light brown & + & + & + & - & - \\
\hline 43/PS2 & P. pseudoalcaligenes & Light green & + & + & + & - & - \\
\hline 52/PS1 & P. pseudoalcaligenes & Light brown & + & + & + & - & - \\
\hline 55/PS1 & P. alcaligenes & Yellow & + & + & + & - & - \\
\hline 64/PS1 & P. alcaligenes & Yellow & + & - & + & - & - \\
\hline 68/PS2 & Pseudomonas aeruginosa & Light brown & + & + & + & - & - \\
\hline 69/PS1 & P. pseudoalcaligenes & Yellow & + & - & + & - & - \\
\hline 71/PS1 & P. pseudoalcaligenes & Yellow & + & + & + & - & - \\
\hline 73/PS1 & P. pseudoalcaligenes & Light brown & + & + & + & - & - \\
\hline 77/PS1 & P. pseudoalcaligenes & Light brown & + & + & + & - & - \\
\hline 78/PS1 & P. pseudoalcaligenes & Light brown & + & + & + & - & - \\
\hline 80/PS2 & Pseudomonas fluorescens biovar $\mathrm{V}$ & Light brown & + & + & + & - & - \\
\hline 87/PS1 & P. pseudoalcaligenes & Yellow & + & + & + & - & - \\
\hline 96/PS1 & P. pseudoalcaligenes & Yellow & + & - & + & - & - \\
\hline $98 / \mathrm{PS} 2$ & P. alcaligenes & Cream & + & - & + & - & - \\
\hline 101/PS1 & P. alcaligenes & Cream & + & - & + & - & - \\
\hline 102/PS2 & P. pseudoalcaligenes subspecies citrulli & Cream & + & - & + & - & - \\
\hline $105 / \mathrm{PS} 2$ & P. pseudoalcaligenes & Green-yellow & + & + & + & - & - \\
\hline 106/PS2 & P. pseudoalcaligenes & Green-yellow & + & + & + & - & - \\
\hline 126/PS1 & P. alcaligenes & Cream & + & - & + & - & - \\
\hline 129/PS2 & P. pseudoalcaligenes & Light green & + & - & + & - & - \\
\hline 137/PS4 & P. aeruginosa & Cream & + & + & + & - & - \\
\hline 140/PS1 & P. pseudoalcaligenes & Green-yellow & + & + & + & - & - \\
\hline
\end{tabular}


Table 2. Antimicrobial susceptibility of 32 isolates of Pseudomonas spp. ${ }^{1}$

\begin{tabular}{lcccc}
\hline Antimicrobial agent & $\begin{array}{c}\text { Concentration } \\
(\mu \mathrm{g} / \text { disc })\end{array}$ & Resistant & Intermediate & Susceptible \\
\hline Piperacillin & 100 & 0 & $2(6.2)$ & $30(93.8)$ \\
Piperacillin/tazobactam & 110 & 0 & $2(6.2)$ & $30(93.8)$ \\
Penicillin G (U) & 10 & $32(100)$ & 0 & 0 \\
Amikacin & 30 & 0 & 0 & $32(100)$ \\
Gentamicin & 10 & 0 & 0 & $32(100)$ \\
Ciprofloxacin & 5 & 0 & 0 & $32(100)$ \\
Ceftazidime & 30 & 0 & 0 & $32(100)$ \\
Imipenem & 10 & 0 & 0 & $32(100)$ \\
Sulfamethoxazole/trimethoprim & 25 & $9(28.1)$ & $19(59.4)$ & $4(12.5)$ \\
\hline
\end{tabular}

${ }^{1}$ Results are given as numbers (percents in parentheses).

Pseudomonas fluorescens biovar V was most frequently isolated (38.3\%). Besides, $54.5 \%$ of Pseudomonas spp. were revealed from raw milk cheeses (Leriche et al., 2004), and $50 \%$ of Pseudomonas spp. were obtained from 1-d-old raw milk cheeses (Morales et al., 2005). In a previous study, the incidence of Pseudomonas spp. was $30.5 \%$ from raw milk samples (Uraz and Çıtak, 1998). In addition, $67 \%$ of Pseudomonas spp. in UHT milk was found by Chen et al. (2011). Pseudomonas pseudoalcaligenes and $P$. alcaligenes are encountered rarely in clinical and environmental samples (Kıska and Gilligan, 1999); however, the current study revealed the isolation of $P$. pseudoalcaligenes and $P$. alcaligenes from cheese samples.

In the present study, most of the isolated Pseudomonas spp. were found to produce extracellular enzymes: protease, lipase, and lecithinase. The results of enzyme activity were agreement with Wiedmann et al. (2000), Dogan and Boor, (2003), and Munsch-Alatossava and Alatossava (2006). These enzymatic activities are very important for the dairy industry. Lipase, protease, and lecithinase are potentially able to cause spoilage of the dairy products (Ray, 2004). Such enzymes can degrade the carbohydrates, proteins, and fats of milk, leading to production of noxious end products and, in some cases, to decrease in cheese yield (Richter and Vedamuthu, 2001; Ray, 2004). Several groups of organisms contain members potentially contributing to milk spoilage under certain conditions. This makes the microbial ecology of raw milk and raw milk cheeses very complex and, thus, spoilage is difficult to prevent. Moreover, a need still exists to assess, within each spoilage group, which species can more often occur and affect the quality of raw milk and raw milk cheese (Ercolini et al., 2009).

Bacterial antimicrobial resistance has become a global problem in both the medical and agricultural fields. Antibiotic resistant strains of bacteria are an increasing threat to animal and human health, with resistance mechanisms determined for all known antimicrobials currently available for clinical use in human and veterinary medicine (McDermott et al., 2002). Most Pseudomonas spp. are naturally resistant to penicillin and the majority of related $\beta$-lactam antibiotics (Ryan and Ray, 2004). In our study, all Pseudomonas spp. isolated from homemade cheeses were resistant to penicillin $\mathrm{G}$ and sulphamethoxazole/trimethoprim (28.1\%). Therefore, Pseudomonas spp. had intermediate resistance to piperacillin and piperacillin/tazobactam $(6.2 \%)$, which are $\beta$-lactams, whereas they did not have any resistance to ceftazidime, one other $\beta$-lactam. A paucity of knowledge exists of antimicrobial susceptibility profiles of food-related bacteria, even though antimicrobial sensitivities of clinical Pseudomonas spp., especially $P$. aeruginosa have been well studied. Clinical studies were emphasized that $P$. aeruginosa was resistant to more than 1 antibiotic (Corona-Nakamura et al., 2001; Hsueh et al., 2005; Muthu et al., 2006). In a study from Finland regarding antibiotic resistance of raw milk-associated Pseudomonas spp., the results of the antimicrobial susceptibility of the isolates were considerably similar to our results. The Pseudomonas spp. isolates almost all were sensitive to piperacillin, piperacillin/tazobactam, ciprofloxacin, amikacin, and gentamicin, but susceptibility level of other antimicrobial agents such as ceftazidime and imipenem was variable (Munsch-Alatossava and Alatossava, 2007). Jensen et al., (2001) also found Pseudomonas spp. isolated from environmental samples had no resistance to ciprofloxacin and gentamicin, like our findings.

\section{CONCLUSIONS}

In conclusion, in the present study, Pseudomonas spp. exhibiting spoilage features were isolated mainly from cheeses. The results obtained regarding isolation of this organism from processed milk highlights the need to improve hygienic practices. This type of organism, found in raw milk cheeses, may depend on inadequate pasteurization of milk or use of unpasteurized milk, the extent of cleaning and sanitizing of milking equipment 
and utensils, and the time and temperature of storage. All of the stages in the milk processing chain during manufacturing have to be under control to achieve the quality and safety of dairy products.

\section{REFERENCES}

Bates, J. L., and P. V. Liu. 1963. Complementation of lecithinase activities by closely related pseudomonads: Its taxonomic implication. J. Bacteriol. 86:585-592.

Bhunia, A. K. 2008. Foodborne Microbial Pathogens: Mechanisms and Pathogenesis. Springer, West Lafayette, IN.

Chen, T. R., Q. K. Wei, and Y. J. Chen. 2011. Pseudomonas spp. and Hafnia alvei growth in UHT milk at cold storage. Food Contr. 22:697-701.

CLSI (Clinical and Laboratory Standards Institute). 2007. Performance Standards for Antimicrobial Susceptibility Testing: Seventeenth Informational Supplement. CLSI document M100-S17. CLSI, Wayne, Pennsylvania, PA.

Collins, C. H., P. M. Lyne, and J. M. Grange. 1989. Collins and Lyne's Microbiological Methods (Pseudomonas, Acinetobacter, Alcaligenes, Flavobacterium, Chromobacterium and Acetobacter). 6th ed. Butterworth-Heinemann, Oxford, UK.

Corona-Nakamura, A. L., M. G. Miranda-Novales, B. Leaños-Miranda, L. Portillo-Gómez, A. Hernandez-Chavez, J. Anthor-Rendón, and S. Aguilar-Benavides. 2001. Epidemiologic study of $P$. aeruginosa in critical patients and reservoirs. Arch. Med. Res. 32:238-242.

Cousin, M. A., J. M. Jay, and P. C. Vasavada. 2001. Psychrotrophic microorganisms. Pages 159-166 in Compendium of Methods for the Microbiological Examination of Foods. F. P. Downes and K. Ito, K, ed. American Public Health Association, Washington, DC.

Dogan, B., and K. J. Boor. 2003. Genetic diversity and spoilage potentials among Pseudomonas spp. isolated from fluid milk products and dairy processing plants. Appl. Environ. Microbiol. 69:130 138 .

Ercolini, D., F. Russo, I. Ferrocino, and F. Villani. 2009. Molecular identification of mesophilic and psychrotrophic bacteria from raw cow's milk. Food Microbiol. 26:228-231.

Freeman, D. J., F. R. Falkiner, and C. T. Keane. 1989. New method for detecting slime production by coagulase negative staphylococci. J. Clin. Pathol. 42:872-874.

Garrity, G. M., J. A. Bell, and T. Lilburn. 2005. Order IX. Pseudomonadales. Pages 323-371 in Bergey's Manual of Systematic Bacteriology. Vol. 2. D. J. Brenner, N. R. Krieg, and G. M. Garrity, ed. Springer, New York, NY.

Gennari, M., and F. Dragotto. 1992. A study of the incidence of different fluorescent Pseudomonas species and biovars in the microflora of fresh and spoiled meat and fish, raw milk, cheese, soil and water. J. Appl. Bacteriol. 72:281-288.

Herrera, A. G. 2001. Psychrotrophic microorganisms. Pages 3-11 in Food Microbiology Protocols. J. F. T. Spencer and de A. L. R. Spencer, ed. Humana Press Inc., Totowa, New Jersey, NJ.

Hogg, S. 2005. Essential Microbiology (Microorganisms in Industry). John Wiley and Sons, West Sussex, UK.

Hsueh, P.-R., W.-H. Chen, and K.-T. Luh. 2005. Relationship between antimicrobial use and antimicrobial resistance in gram-negative bacteria causing nosocomial infections from 1991-2003 at a university hospital in Taiwan. Int. J. Antimicrob. Agents 26:463-472.

Jensen, L. B., S. Baloda, M. Boye, and F. M. Aarestrup. 2001. Antimicrobial resistance among Pseudomonas spp. and Bacillus ce- reus group isolated from Danish agricultural soil. Environ. Int 26:581-587.

Kiska, D. L., and P. H. Gilligan. 1999. Pseudomonas. Pages 517-525 in Manual of Clinical Microbiology. P. R. Murray, E. J. Baron, M. A. Pfaller, F.C. Tenover, and R. H. Yolken, ed. American Society for Microbiology Press, Washington, DC.

Leriche, F., A. Bordessoules, K. Fayolle, R. Karoui, K. Laval, L. Leblanc, and E. Dufour. 2004. Alteration of raw-milk cheese by Pseudomonas spp.: Monitoring the sources of contamination using fluorescence spectroscopy and metabolic profiling. J. Microbiol. Methods 59:33-41.

McDermott, P. F., S. Zhao, D. D. Wagner, S. Simjee, R. D. Walker, and D. G. White. 2002. The food safety perspective of antibiotic resistance. Anim. Biotechnol. 13:71-84.

Meghwanshi, G. K., L. Agarwal, K. Dutt, and R. K. Saxena. 2006 Characterization of 1,3-regiospecific lipases from new Pseudomonas and Bacillus isolates. J. Mol. Catal., B Enzym. 40:127-131.

Moore, E. R. B., B. J. Tindall, V. A. P. M. Dos Santos, D. H. Pieper J. Ramos, and N. J. Palleroni. 2006. Nonmedical: Pseudomonas. Pages 646-703 in The Prokaryotes. Vol. 6. M. Dworkin, S. Falkow, E. Rosenberg, K. H. Schleifer, and E. Stackebrandt, ed. Springer, New York, NY.

Morales, P., E. Fernandez-Garcia, and M. Nunez. 2005. Volatile compounds produced in cheese by Pseudomonas strains of dairy origin belonging to six different species. J. Agric. Food Chem. 53:68356843.

Munsch-Alatossava, P., and T. Alatossava. 2006. Phenotyping characterization of raw milk-associated psychrotrophic bacteria. Microbiol. Res. 161:334-346.

Munsch-Alatossava, P., and T. Alatossava. 2007. Antibiotic resistance of raw-milk-associated psychrotrophic bacteria. Microbiol. Res. 162:115-123.

Muthu, S. E., R. A. Aberna, V. Mohan, G. Premalatha, R. S. Srinivasan, S. P. Thyagarajan, and U. A. Rao. 2006. Phenotypes of isolates of $P$. aeruginosa in a diabetes care center. Arch. Med. Res. 37:95-101.

Ray, B. 2004. Fundamental Food Microbiology. CRC Press, Boca Raton, FL.

Richter, R. L., and E. R. Vedamuthu. 2001. Milk and Milk Products. Pages 483-495 in Compendium of Methods for the Microbiological Examination of Foods. F. P. Downes and K. Ito, ed. American Public Health Association, Washington, DC.

Ryan, K. J., and C. G. Ray. 2004. Sherris Medical Microbiology. 4th ed. McGraw Hill, New York, NY.

Sorhaug, T., and L. Stepaniak. 1997. Psychrotrophs and their enzymes in milk and dairy products: Quality aspects. Trends Food Sci. Technol. 8:35-41.

Uraz, G., and S. Citak. 1998. The isolation of Pseudomonas and other gram $(-)$ psychrotrophic bacteria in raw milks. J. Basic Microbiol. 38:129-134.

Vermelho, A. B., M. N. L. Meirelles, A. Lopes, S. D. G. Petinate, A. A. Chaia, and M. H. Branquinha. 1996. Detection of extracellular proteases from microorganisms on agar plates. Mem. Inst. Oswaldo Cruz 91:755-760.

Wiedmann, M., D. Weilmeier, S. S. Dineen, R. Ralyea, and K. J. Boor. 2000. Molecular and phenotypic characterization of Pseudomonas spp. isolated from milk. Appl. Environ. Microb. 66:2085-2095.

Yahr, T. L., and M. R. Parsek. 2006. Pseudomonas aeruginosa. Pages 704-713 in The Prokaryotes. Vol. 6. M. Dworkin, S. Falkow, E. Rosenberg, K. H. Schleifer, and E. Stackebrandt, ed. Springer, New York, NY. 